\title{
0 que um inventário de referências culturais poderá dizer? Os desafios da atuação dos antropólogos nos processos de mapeamento, identificação e registro do patrimônio cultural das populações afro-brasileiras
}

Ana Paula Comin de Carvalho (UFRB)
Procuro refletir neste artigo sobre os desafios da atuação dos antropólogos nos processos de mapeamento, identificação e registro do patrimônio cultural das populações afro-brasileiras, a partir de minha experiência na elaboração do Inventário de Referências Culturais sobre o Massacre de Porongos'.

$\mathrm{O}$ “Massacre de Porongos" ocorreu na madrugada de 14 de novembro de 1844 nas imediações do Cerro de Porongos, no distrito de Torrinhas, do então município de Piratini, no estado do Rio Grande do Sul. Parte de um dos destacamentos de lanceiros negros ${ }^{2}$ do exército farroupilha, que estava sob o comando do General Davi Canabarro, foi atacada pelas tropas imperiais. A localidade referida pertence atualmente à cidade de Pinheiro Machado, na região Sul do estado, situando-se a aproximadamente 378 quilômetros da capital.

Esta seria mais uma das batalhas perdidas pelos farrapos ao longo da revolução farroupilha ${ }^{3}$. Todavia, estava em curso um processo de negociação de paz entre as partes, no âmbito do qual o Império do Brasil não concordava em premiar com a liberdade os cativos insurretos que integravam o exército farroupilha. Outrossim, parcelas da elite gaúcha envolvida no conflito - estancieiros criadores de gado e produtores de charque com base em mão de obra escrava - temiam que estes negros politizados e militarizados pudessem se somar a outros num levante contra a ordem vigente. Adiciona-se a isso uma carta, atribuída ao Barão de Caxias, representante do Império que buscava dar fim à revolta, endereçada ao Coronel Francisco Pedro de Abreu, o Moringue, comandante das tropas imperiais que atacaram os lanceiros negros em Porongos. A missiva fornecia a localização do exército farrapo e dava instruções para poupar sangue branco e indígena e facilitar a fuga do General Davi Canabarro.

A polêmica em torno desse fato, polarizada pelas teses de surpresa de Moringue, ou traição de Canabarro, foi gestada entre pesquisadores da história do Rio Grande do Sul desde o final do século XIX. Ela perdeu prestígio nesse meio 
entre as décadas de 1920 e 1930 e ressurgiu no intervalo de 1970 a 1980 em virtude de produções de militantes dos movimentos sociais negros e de pesquisas acadêmicas com novas abordagens. No entanto, a maior parte da população ainda ignorava esse acontecimento histórico.

Essa situação começou a mudar a partir de 2000, quando ocorreram algumas iniciativas relacionadas com a valorização do negro no estado, protagonizadas por militantes ou simpatizantes da causa, que acionavam a figura dos lanceiros e o ataque sofrido por eles. Parte destas ações se projetou sobre o lugar onde esses soldados foram atacados, configurando uma mobilização política pela construção de um memorial no local e pelo seu tombamento.

Desde então, a controvérsia histórica gradativamente ganhou contornos de reconhecimento do patrimônio cultural dos negros do Rio Grande do Sul em nível nacional e passou a dizer respeito não apenas a pesquisadores ou estudiosos, mas também a integrantes dos movimentos sociais negros, representantes das esferas municipal, estadual e federal do poder público, políticos, arquitetos, arqueólogos, entre outros.

Antes da inserção de uma antropóloga nesse processo, ocorreram tentativas de legitimação das demandas pela construção do memorial e pelo tombamento do Cerro de Porongos. Diversos agentes, principalmente aqueles envolvidos na luta anti-racista, buscavam salientar a importância dos lanceiros negros na Revolução Farroupilha, o que justificaria uma intervenção no local em que estes soldados travaram a sua última batalha sob a promessa de liberdade.

No entanto, esses discursos não conseguiram gerar por si sós a completa certeza da pertinência desses pleitos. Os sujeitos que os promoveram não eram vistos como interlocutores plenamente eficazes para o diálogo com os campos administrativo, político e jurídico, porque lhes faltava a legitimidade técnica ou acadêmica que a situação parecia requerer. Outrossim, nenhuma dessas investidas considerava o discurso dos moradores de Pinheiro Machado e dos arredores do cerro sobre o Massacre de Porongos. Na busca pela legitimação desses discursos gerou-se uma grande expectativa de que a palavra autorizada sobre essas questões seria a dos antropólogos. Mas como isso acontece neste caso? Quais são os motivos que levam os agentes envolvidos a pensar tal coisa? É o que veremos agora.

Entre 2002 e 2004, apenas as Superintendências Regionais do Instituto do Patrimônio Histórico e Artístico Nacional (IPHAN) dos estados do Maranhão, do Rio de Janeiro e da Bahia tinham desenvolvido inventários de bens culturais relacionados à população negra (o Bumba Meu-Boi no Maranhão, o Jongo no Sudeste e o Acarajé na Bahia). Desse modo, não existiam experiências em âmbito regional que servissem de parâmetro para a atuação dos órgãos estatais no que se refere ao tema do patrimônio cultural afro-brasileiro. O Inventário de Referências Culturais sobre o Massacre de Porongos foi, portanto, o primeiro estudo desta natureza a ser desenvolvido no estado do Rio Grande do Sul'.

Em maio de 2004, quando segmentos do movimento negro gaúcho demandaram o tombamento do Cerro de Porongos, a legislação federal referente ao tema previa a realização de projetos de identificação, reconhecimento, salvaguarda e promoção da dimensão imaterial do patrimônio cultural. Esse processo se dava através de parcerias do IPHAN com outras instituições dos governos federal, estadual e municipal; universidades; organizações 
não-governamentais; agências de desenvolvimento e organizações privadas ligadas à cultura, à pesquisa e ao financiamento. Tais parcerias objetivavam implementar a política de inventário, registro e proteção a esse tipo de bem.

Com as mudanças nas concepções sobre o patrimônio no Brasil, novos sujeitos passaram a intervir nesse campo político outrora dominado por arquitetos (Tamaso 2005). Nesse contexto de expansão do conceito, tanto antropólogos quanto folcloristas, que se dedicavam ao estudo das manifestações culturais populares a partir de perspectivas epistemológicas distintas, tiveram suas possibilidades profissionais ampliadas. Considerando que, quando da constituição das ciências sociais no país, o folclore não conseguiu se estabelecer como um saber científico ${ }^{5}$; que a metodologia do inventário de referências culturais foi aprimorada por um antropólogo; e que o manual de aplicação desse tipo de pesquisa recomendava que a equipe de estudo fosse composta por pessoas oriundas das ciências sociais, particularmente da antropologia, podemos dizer que o primeiro segmento foi aquele que obteve maior êxito em ocupar este novo lugar no processo de patrimonialização dos sentidos atribuídos a práticas e lugares até então sem reconhecimento estatal.

O surgimento da categoria jurídica patrimônio cultural brasileiro foi antecedido pela discussão em torno dos Monumentos Negros que resultou no tombamento do Terreiro de Candomblé da Casa Branca (Salvador, BA) em 1984 e da Serra da Barriga (União dos Palmares, AL) em 1985. Esta última experiência, em particular, na qual militantes dos movimentos sociais negros de todo o país tiveram intensa participação, moldava as expectativas de segmentos da população negra gaúcha em relação às novas políticas patrimoniais. Ou seja, buscava-se a valorização da figura dos lanceiros negros como ícones da luta por liberdade empreendida pelos negros no Brasil, esperando-se que tal pleito tivesse o mesmo êxito observado em relação a Zumbi dos Palmares.

No âmbito da antropologia, as reflexões mais sistemáticas sobre o patrimônio começavam a tomar corpo, em especial após a criação do Grupo de Trabalho da Associação Brasileira de Antropologia (ABA) sobre Patrimônio Cultural em 2002. Poucos inventários de referências culturais realizados sob a coordenação de antropólogos tinham sido finalizados, sendo menor ainda o número de artigos, dissertações ou teses que abordassem estas experiências nesse período 6 . Outrossim, a diversidade de temas que agora passavam a ser abordados sob esta perspectiva (povos indígenas, comunidades quilombolas, usos e sentidos atribuídos a espaços tombados, festas populares e religiosas, feiras, produção de alimentos e seus usos) tornava ainda mais difícil a comparação e o estabelecimento de consensos sobre o assunto. Neste aspecto, cada novo estudo era inédito, e um grande leque de possibilidades interpretativas se apresentava aos pesquisadores envolvidos nesses projetos.

A realização de um inventário sobre o Massacre de Porongos fomentou a expectativa de que outras manifestações culturais afro-brasileiras existentes no estado do Rio Grande do Sul viessem a ser reconhecidas como patrimônio cultural. Um exemplo disso é a solicitação de registro do Maçambique ${ }^{7}$ apresentada à Superintendência Regional do IPHAN por integrantes do grupo e apoiada pelo antropólogo losvaldyr Carvalho Bittencourt Jr., que desenvolveu pesquisa sobre o tema para sua tese de doutorado (Bittencourt Jr. 2006). 
No primeiro semestre de 2004, a Superintendência Regional do IPHAN já possuía os recursos financeiros necessários para a realização da primeira etapa do Inventário sobre o Massacre de Porongos, ou seja, para fazer o levantamento preliminar de informações sobre o tema, mas não tinha uma equipe de pesquisa contratada para a execução desse trabalho.

Aos moldes do que ocorrera em relação à elaboração de uma cartilha sobre o Negro no Rio Grande do Sul, o movimento social negro pressionava a instituição para que os pesquisadores partícipes do inventário fossem indicados pela militância. Contudo, o desenvolvimento daquele material, elaborado por profissionais com engajamento nas lutas políticas do movimento negro, fora bastante problemático na perspectiva dos servidores do Instituto, em especial no que se refere ao "tom" dos textos produzidos pelos contratados. Isto implicou que os mesmos fossem revisados e organizados por uma técnica da instituição, a fim de que se aproximassem mais daquilo que era esperado pelos órgãos financiadores (Souza 2005).

Por outro lado, como nenhum inventário de referências culturais havia sido realizado no Rio Grande do Sul até então, não existiam pesquisadores locais com experiência na execução desse tipo de pesquisa. Nesse contexto, a funcionária do IPHAN no estado responsável pelas políticas relativas ao patrimônio imaterial, que também era historiadora, solicitou indicações de profissionais a um professor de antropologia da Universidade Federal do Rio Grande do Sul dedicado aos estudos das populações indígenas da região, que já participara do quadro técnico do órgão em período anterior e que iria coordenar o inventário sobre a relação dos Mbya-Guarani com o sítio histórico das reduções jesuíticas em São Miguel das Missões.

Ele recomendou uma professora de antropologia da mesma universidade que já tinha se aposentado, mas que ao longo de sua carreira docente tinha desenvolvido pesquisas sobre negros em processo de ascensão social e orientado estudos de alunos de graduação e pós-graduação relacionados à temática, além de ter coordenado o relatório sobre a Comunidade Remanescente de Quilombo de Morro Alto.

Em meados do mês de junho, a servidora entrou em contato com ela e marcou uma reunião. No dia desse encontro, acabei acompanhando essa professora até a sede da Superintendência Regional do IPHAN e participando da conversa em que o convite para que ela coordenasse o inventário foi formalizado. Imediatamente me engajei no projeto, colaborando na elaboração do orçamento, composição da equipe de pesquisa e de um cronograma de atividades ${ }^{8}$.

Umas das primeiras expectativas com a qual os pesquisadores se depararam advinha da própria instituição que os contratava e estava relacionada com a metodologia de aplicação do inventário. Esta última, que foi aprimorada pelo antropólogo Antonio Augusto Arantes, previa que o mesmo fosse realizado em três etapas consecutivas, quais sejam: levantamento preliminar, identificação e documentação dos bens culturais. Na primeira fase, além de mapear todas as referências de acordo com as classificações estabelecidas (saberes, celebrações, formas de expressão e lugares) num sítio e localidades previamente determinados, era preciso definir quais delas deveriam ser identificadas e documentadas posteriormente, tendo em vista a relevância das mesmas para a configuração das identidades sociais dos grupos estudados. 
A apropriação contemporânea dos lanceiros negros e do Cerro de Porongos não estava restrita a uma cidade ou região específica do Rio Grande do Sul, destacando-se naquele momento em alguns municípios que, durante a Revolução Farroupilha, foram capitais (Piratini e Caçapava do Sul) ou palco de batalhas importantes desse conflito (Guaíba, Porto Alegre e Pinheiro Machado). Como a unidade territorial que abrangia todas essas localidades era o estado do Rio Grande do Sul, acabamos indicando-o como sítio do inventário. Tal escolha permitiria a inclusão, se fosse o caso, de outras cidades nas etapas seguintes.

A maior parte das informações coletadas na pesquisa de campo parecia não se enquadrar nas categorias de bens culturais existentes. As celebrações em homenagem aos lanceiros negros, que participavam fortemente da produção de sentidos específicos de lugar e território à localidade onde ocorreu o massacre, estavam em processo de consolidação. O reconhecimento da distintividade do cerro era tematizado em diferentes narrativas sobre o que lá teria ocorrido que prescindiam da apropriação do local por práticas e atividades de natureza variada. Muitos indivíduos se reportavam ao evento sem conhecer o local onde ele se desenrolou. Tratava-se de um espaço que era apoderado, principalmente, em termos de memória, de imaginário. Estas histórias e/ou estórias permitiam a identificação das pessoas que as narravam com uma determinada coletividade: movimento tradicionalista, movimento negro, comunidade acadêmica, extrapolando as fronteiras físicas e culturais de uma localidade e interligando estes sujeitos a outros que viviam em cidades distantes, mas que compartilhavam experiências históricas marcantes que eram constitutivas de seus modos de imaginação, cognição e ação, bem como de sua identidade regional, como a Guerra Farrapa (Grimson 2003). Na medida em que a metodologia do inventário não contemplava as formas de expressão linguísticas, como poderíamos mapear uma referência cultural que se materializava na atividade de narrá-la? Em decorrência disso, propusemos ao IPHAN a criação de uma nova classificação de bem cultural - narrativas - que teria a seguinte conceituação: contos, histórias, estórias, lendas e causos significativos para um grupo social de uma determinada região, constitutivas de sua identificação para com essa coletividade, compartilhadas e transmitidas através das gerações seja por meio oral ou escrito. Com ela poderíamos enquadrar narrativas históricas, lendárias, ficcionais, entre outras, atentando para as suas variações que dependeriam das formas de produção, reprodução e circulação deste bem cultural, pois a identidade narrativa não cessa de se fazer e de se desfazer (Ricœur 1997).

Dentre os diversos bens culturais mapeados no levantamento preliminar, indicamos o Cerro de Porongos e as narrativas sobre o massacre dos lanceiros negros para posterior identificação e documentação nas fases seguintes, uma vez que eram estas as referências que pareciam ter maior afinidade com o tema central da pesquisa. A avaliação de que o evento em que os soldados negros foram atacados pelas tropas imperiais era o elemento central do processo que estudávamos fez com que mudássemos a denominação original do trabalho - atribuída pelos servidores do IPHAN - de "Inventário sobre o Sítio Histórico de Porongos" para "Inventário sobre o Massacre de Porongos".

A princípio os funcionários do IPHAN tinham dúvidas se o tombamento solicitado pelos militantes negros era o instrumento apropriado nessa situação, principalmente em virtude da mobilização pela construção do 
memorial, que implicaria modificações na paisagem ${ }^{9}$ do local. Nesse sentido, o registro parecia mais adequado, pois se tratava de um mecanismo menos restritivo às intervenções que eles buscavam promover. A realização do inventário já apontava para esta direção. Tratava-se de uma ação que antecedia a inscrição de um determinado bem cultural no livro de registro específico. No entanto, depois de novembro de 2004, quando ocorreu uma celebração em homenagem aos lanceiros negros em Pinheiro Machado, com a presença de mais de seiscentas pessoas, tanto os pesquisadores quanto os servidores questionavam suas perspectivas iniciais em relação ao tema. Este contexto fez com que, na fase de identificação dos bens culturais, duas geógrafas fossem incorporadas à equipe de pesquisa, com o objetivo de produzir um mapa onde estivessem localizados os espaços referidos nas narrativas locais sobre o massacre e um relatório sobre as fragilidades e potencialidades físicas do cerro. Em seu diagnóstico, as pesquisadoras sugeriram o tombamento do lugar, cujo perímetro deveria incluir os pontos de memória sobre o evento.

Outrossim, como veremos a seguir, existiam outras expectativas em relação ao inventário, que advinham de diferentes agentes envolvidos no processo de mobilização de construção do memorial, e com as quais os pesquisadores tiveram que lidar.

A Fundação Cultural Palmares firmou em novembro de 2003 um protocolo de intenções com os governos do estado do Rio Grande do Sul e do município de Pinheiro Machado que previa, entre outras coisas, a realização de estudos para verificar a pertinência do tombamento do Cerro de Porongos. Em decorrência disso, quando iniciamos as atividades do inventário nesta cidade, as pessoas que procuramos acreditavam que se tratava de uma iniciativa desse órgão. O secretário municipal das pastas de Educação, Cultura e Desporto e Indústria, Comércio e Turismo, e uma liderança do movimento negro local, os primeiros com quem fizemos contato na localidade, revelaram-se surpresos quando explicamos que aquela era uma ação do IPHAN. Além da existência do protocolo de intenções, outro fator colaborava para essa confusão: as duas instituições estavam ligadas ao Ministério da Cultura e desenvolviam políticas de valorização do patrimônio cultural afro-brasileiro. Contudo é importante frisar que a Fundação, oriunda da mobilização pelo tombamento da Serra da Barriga no fim da década de 1980, vinha desde a sua criação trabalhando com o tema, enquanto o Instituto passou a tratá-lo de maneira mais sistemática muito recentemente.

Além disso, muitos acreditavam que a demora na construção do memorial estaria relacionada à realização de nosso trabalho. Cada vez que retornávamos a Pinheiro Machado éramos indagados pelos representantes da administração municipal ou do movimento negro local sobre o tema, ainda que sempre salientássemos que se tratava de coisas distintas, que se desenrolavam de maneira independente uma da outra.

À medida que íamos conversando com as pessoas envolvidas no processo de apropriação contemporâneo dos lanceiros negros e do Cerro de Porongos que residiam nas localidades, percebíamos que muitas delas esperavam que a pesquisa apontasse a "verdade"10 sobre o que teria acontecido aos soldados farrapos que lutavam sob a promessa de liberdade: ataque-surpresa dos imperiais ou traição dos seus comandantes, pondo fim à polêmica histórica sobre este evento, ou ainda revelando qual seria o local exato em que eles teriam sido massacrados. 
O desencontro de informações e versões sobre este fato suscitava dúvidas acerca do caráter do confronto entre farrapos e imperiais, do número de lanceiros negros mortos no local e do destino dos sobreviventes. Nesta conjuntura, historiadores e arqueólogos adquiriram grande importância, pois eram os profissionais considerados capazes de fornecer respostas a estas questões a partir de evidências materiais (documentos ou vestígios).

O temor em relação a esse tipo de expectativa fez com que o historiador primeiramente procurado para compor a equipe do inventário se recusasse a participar do projeto quando do seu início. Ciente desse anseio, um arqueólogo, apoiado pelo Museu Antropológico do Rio Grande do Sul, apresentou ao IPHAN no ano de 2005 um projeto de prospecção do Cerro de Porongos, com vistas a obter a autorização da instituição para realizar tal investigação no local. Em outubro desse mesmo ano, ele visitou a cidade de Pinheiro Machado e ministrou um curso de escavações arqueológicas, com aulas teóricas e práticas, para os integrantes do movimento negro local e professores das redes estadual e municipal. Por mais que esclarecêssemos nossos informantes de que não era nosso objetivo fornecer uma posição definitiva sobre o caráter do Massacre de Porongos, éramos sistematicamente incitados por eles a expressar nossa opinião sobre a controvérsia.

Ao instituir as diferentes leituras do massacre como objeto de identificação do inventário para apontar a importância do Cerro de Porongos para vários grupos e para a conformação de identidades sociais, a pesquisa colocou a leitura da traição num patamar equivalente ao da surpresa, condição de que não usufruía até então. Isto obrigou os adeptos desta última tese a contra-argumentar de forma mais frequente e a apresentar novas explicações para esse fato e para outros contemporâneos que a ele são relacionados pelos militantes negros. Dentre os exemplos desse fenômeno podemos mencionar o de um tradicionalista e pesquisador de Caçapava do Sul que, na primeira etapa da pesquisa, contestava, veementemente, a versão de traição e que depois passou a alegar que o Barão de Caxias teria sido traído por Francisco de Abreu, o Moringue, na medida em que este último comandou um ataque das tropas imperiais aos soldados farrapos num período em que o primeiro, seu superior, buscava encerrar o conflito de forma pacífica e negociada.

Um movimento inverso também podia ser observado na medida em que os adeptos da interpretação da traição passaram a modificar elementos de suas narrativas. Um militante negro de Porto Alegre, que produzia obras de arte sobre os lanceiros negros e que participava das reuniões da Comissão Pró-memorial, sempre enfatizava a traição de Canabarro. No final da pesquisa, ele passou a considerar os demais líderes farroupilhas e imperiais tão desleais quanto o primeiro. Outrossim, nas estórias sobre o Massacre de Porongos mapeadas ao longo do inventário, assim como naquelas recolhidas pelo antropólogo Carlos Alberto Steil (1996) entre os romeiros que se dirigem para o Santuário de Bom Jesus da Lapa, na Bahia, oralidade e escrita (narrativas que ouviram de conhecidos e antepassados e informações de publicações sobre a Revolução Farroupilha) não só se misturavam como se reforçavam mutuamente, colocando em movimento a circulação entre mito e história.

Alguns agentes detentores de papéis importantes nos momentos iniciais do processo de mobilização pela construção do memorial, e que se encontravam afastados desse contexto em decorrência das disputas pelo protagonismo nesse pleito, esperavam que a pesquisa lhes propiciasse o reconhecimento social necessário ao 
seu reingresso nessa arena. Na oportunidade em que a equipe do inventário apresentou os resultados da etapa de identificação aos interessados na sede regional do IPHAN, um deles expressou inconformidade com a referência feita a grupos que tinham se envolvido posteriormente com a questão e demandou um destaque maior aos idealizadores do movimento reivindicatório.

Traçando um paralelo com o que aponta Silva (2005) em relação à antropologia na identificação e delimitação de terras indígenas, os inventários de referências culturais afro-brasileiras contribuem, decisivamente, para uma reestruturação do campo de forças entre este segmento e a sociedade envolvente. Isso se dá pela proposição, via relatórios antropológicos, de integração de segmentos desta população, seus territórios e suas referências culturais a sistemas administrativos mais amplos e regulados pelo Estado nacional. Em outras palavras, os inventários propiciam cenários para a realização de uma reflexão antropológica sobre o poder, bem como sobre os seus efeitos sobre o antropólogo e o seu campo de atuação, em especial por se encontrarem aí embaralhadas posições e ideias costumeiramente associadas a uma experiência etnográfica tradicional.

Neste contexto de pesquisa, os militantes esperavam que os profissionais contratados fossem negros com engajamento político. Esta expectativa se baseava na crença generalizada de que os pesquisadores brancos negariam ao negro a condição de sujeito, e que o campo de produção de conhecimento era um lugar de poder que poderia e deveria ser objeto de disputa, tendo em vista os negros estarem subrepresentados nele. A frustração destas esperanças suscitou situações em que se tentou identificar os posicionamentos políticos e teóricos dos pesquisadores a fim de se certificar do comprometimento deles com as demandas do grupo estudado.

Em relação ao Massacre de Porongos, o fato de os militantes serem nossos informantes e acompanharem de perto o desenvolvimento da pesquisa, vislumbrando seus resultados parciais através das situações de retorno das informações coletadas que realizamos ao longo das fases de identificação e documentação, parece ter atenuado as suspeitas que poderiam pairar sobre a equipe, ou ao menos a explicitação recorrente das mesmas através de ações ou palavras.

Outro desejo dos militantes era que os estudos confirmassem as crenças forjadas na sua mobilização política, legitimando, dessa forma, discursos e grupos sociais: o Massacre de Porongos fora uma traição. Tendo em vista a importância destas questões para essa coletividade, optamos por estabelecer um diálogo com este tema em outros termos, evidenciando os sentidos mobilizadores e identitários que estas interpretações possuíam para seus integrantes. Desse modo, as diferentes interpretações sobre o Massacre de Porongos foram consideradas variações de uma narrativa sobre um evento histórico que deveria ser identificada enquanto um bem cultural passível de registro como patrimônio cultural.

O fato de não integrar ou apoiar, explicitamente, nenhuma organização social do movimento negro produzia uma relativa confiança da instituição que nos contratava de que nosso trabalho seria menos "político" e mais técnico, mas que - paradoxalmente - deveria dar as respostas necessárias às ações políticas, legitimando decisões neste campo e revestindo-as de um caráter científico. O inventário sobre o Massacre de Porongos deveria orientar a ação do IPHAN em relação às demandas do movimento negro pela construção do memorial e pelo tombamento do local. 
Estes presumíveis compromissos - com o movimento negro e/ou com os órgãos estatais - alimentam a desconfiança da academia quanto à atuação de pesquisadores nesses tipos de temas e trabalhos. No que se refere à questão do patrimônio cultural, problematiza-se o poder que o pesquisador tem de definir os bens que serão reconhecidos, em detrimento de outros (Abreu 2005), e as consequências disso para os grupos sociais vinculados a eles (Tamaso 2005). Outrossim, tem-se a impressão de que estes estudos seriam algo menor, menos acadêmico do que uma dissertação ou tese (O'Dwyer 2005).

Como aponta Schuch (2002), existe uma tentativa de distinção entre "operadores" e "teóricos" no campo da antropologia. Enquanto se desconfia que os primeiros não sejam capazes de formular boa teoria porque lhes falta a isenção necessária para tanto, suspeita-se que os últimos tendem a produzir idéias excessivamente abstratas e incompatíveis com a realidade, já que se dedicam exclusivamente à academia.

A representação que se busca impor é a de que esse espaço não comporta "operadores", mas apenas "teóricos", e que a academia é o lugar por excelência, se não o único possível, de atuação para um antropólogo. Fora dela, toda ação tende a ser vista como perigosa. O trabalho etnográfico, enquanto contato do pesquisador com o mundo exterior, só se torna possível porque já está estabelecido como uma prática antropológica legítima. No entanto, o âmbito de circulação da teoria produzida a partir da experiência dificilmente extrapola os limites da academia, resumindo-se a uma ação estratégica do antropólogo em sua trajetória dentro do próprio meio.

Se no campo jurídico a divisão feita entre "sagrados" e "profanos" se dá pelo compartilhamento (ou não) dos valores inerentes a esse microcosmo, na antropologia parece que qualquer teórico ou teoria que se preste explicitamente a uma causa se torna "profano" (Bourdieu 1998). A posição de uma "antropologia pela antropologia", que serviu para criar uma autonomia relativa do campo, poderia também apartar o saber antropológico de contextos de conflito em que ele poderia fazer diferença tanto em termos práticos quanto teóricos, já que a interlocução com causas ou instituições de intervenção tensiona a teoria e multiplica os problemas científicos, produzindo dados e subsídios (Pereira 2007).

De fato, a maior parte das discussões sobre o papel do antropólogo tem por base a distinção entre uma antropologia acadêmica (mais teórica) e uma aplicada (mais prática): seja como duas margens de um rio por onde o pesquisador pode navegar em movimento de zigue-zague (Fonseca 2004/2005), ou ainda como lados opostos de um muro, tomando-se muitas vezes como dada a separação entre a teoria e a prática, à medida em que estas duas dimensões do conhecimento são visualizadas como campos diferentes, que operam com lógicas distintas e formas de reconhecimento e legitimação diferenciadas (Silva 2008). Mas será que é realmente possível distinguir uma coisa da outra?"11

Sobre essa questão, é pertinente evocar aqui as considerações de L'Estoile, Neiburg e Sigaud (2002). Segundo eles, a oposição ciência versus política é frequentemente utilizada para pensar os vínculos entre as atividades desempenhadas pelos indivíduos como "pesquisadores" e como "cidadãos", bem como para refletir sobre as dificuldades em conciliar as exigências do pertencimento à comunidade científica com o engajamento nos debates e nas lutas políticas, filiações vividas como potencialmente contraditórias. 
Essa interpretação oculta a existência de relações constitutivas entre a prática científica, a formação e o funcionamento dos Estados. Uma análise histórica e comparada permite colocar em evidência uma relação de dependência mútua entre a ação política, a elaboração e a implementação de políticas estatais por parte dos agentes da administração e a produção de conhecimento sobre as populações que estes administram.

Como sugerem os autores, estamos diante de uma modalidade específica de relação entre espaço burocrático e forma de produção intelectual, modalidade que se torna passível de análise na medida em que estabelecemos analogias. Ao compararem a situação do clérigo em relação ao Estado, analisada por Max Weber, com a vivida pelos acadêmicos, L'Estoile et al. (2002) conseguem mostrar que não são contraditórias as reivindicações de autonomia e os conflitos de fronteira entre o mundo do saber e o mundo da política.

As denúncias de comprometimento de pesquisadores com determinados grupos sociais apresentadas no interior do espaço acadêmico são feitas em nome do ideal da pureza científica, da mesma maneira que as acusações de comprometimento de clérigos com o mundo, o poder e a riqueza eram feitas no interior do espaço religioso em nome do ideal da pureza religiosa. O que permite aos acadêmicos, assim como aos clérigos em momento anterior, reivindicar autonomia em relação ao poder político estatal é o fato de prestarem ao Estado serviços decisivos, garantindo, ao mesmo tempo, a legitimação de seu poder, o fornecimento de especialistas para a administração estatal e a formação dos agentes políticos e técnicos.

Sendo assim, a autonomia da ciência deve ser tomada como uma categoria nativa que se define, em grande parte, em relação ao que lhe é exterior. Nesse sentido, em vez de determinar o grau de autonomia da produção acadêmica, devemos identificar as relações de solidariedade e oposição estrutural entre os mundos da ciência e da política. No caso da antropologia brasileira, como aponta o antropólogo Antonio Carlos de Souza Lima (2002) ao tratar do indigenismo no país, sua consolidação como disciplina acadêmica e universitária, principalmente a partir da década de 1960, só pode ser compreendida considerando-se a influência dos antropólogos e de suas pesquisas na formulação de políticas estatais voltadas para as populações indígenas.

A partir dos anos 1980, em virtude de uma política estatal de formação de um sistema nacional de ensino e pesquisa que exigiu a ampliação de quadros qualificados nas universidades, vários programas de pós-graduação em antropologia foram criados. A estreita relação entre pesquisas antropológicas e Estado também pode ser observada quando atentamos para as principais fontes de financiamento das investigações: a Coordenação de Aperfeiçoamento de Pessoal de Nível Superior (CAPES) e o Conselho Nacional de Desenvolvimento Científico e Tecnológico (CNPq), instituições ligadas, respectivamete, ao Ministério da Educação e ao Ministério da Ciência e Tecnologia.

De outro lado, a própria Associação Brasileira de Antropologia atribuiu-se a função de promover a disciplina junto aos poderes públicos, constituindo-se num importante grupo de pressão que busca intervir na definição das políticas estatais para garantir os direitos das populações que seus afiliados estudam (L'Estolie et al. 2002).

Quando o campo dos antropólogos é o patrimônio, como coloca Abreu (2005), uma série de outras questões se apresenta para os pesquisadores. Podemos hierarquizar culturas, isto é, selecionar manifestações culturais em 
prejuízo de outras? Devemos certificar culturas através do registro como patrimônio cultural? Mas como deixar de fazê-lo quando são nossos próprios objetos de estudo e sabemos que isso pode ser uma boa estratégia para a autoafirmação e a construção da autoestima de determinados grupos sociais? Não estaríamos correndo o risco de congelar manifestações culturais através da imagem cristalizada do registro? A autora não se propõe a responder estas perguntas, lançando-as para uma reflexão futura que os "antropólogos do patrimônio" devem fazer.

Textos como o de Velho (2007) sobre o tombamento do terreiro de candomblé Casa Branca parecem reafirmar o que dizem L'Estoile et al. (2002): os antropólogos, assim como os demais envolvidos nesses processos, são partes interessadas nas lutas em torno da definição do Estado, do seu papel e das políticas que devem ser levadas a cabo. Diante de quadros complexos e conflituosos, é crucial ao pesquisador perceber e compreender os diferentes pontos de vista em jogo para poder avaliar os custos e ganhos das decisões que são tomadas e dos valores que as sustentam.

Estávamos cientes de que a política patrimonial não reconheceu a participação popular na Revolução Farroupilha. Não era o caso de hierarquizar, mas de propiciar a inclusão de um grupo historicamente invisibilizado na história do Rio Grande do Sul. A seleção deste tema configurava um precedente para outros pleitos de grupos minoritários, assim como possibilitava a configuração de uma identidade negra local mais positiva e de uma identidade regional mais plural. Por fim, o possível registro das narrativas sobre o Massacre de Porongos poderia produzir uma valorização dessas interpretações que até então eram marginalizadas.

A antropóloga Eliane Cantarino O'Dwyer (2005), ao fazer uma reflexão sobre as condições e possibilidades do fazer antropológico tendo por base três experiências de pesquisa suas - um parecer sobre violações de direitos de populações seringueiras no estado do Acre, outro sobre comunidades remanescentes de quilombos dos rios Trombetas e Erepecuru no Pará, e um laudo sobre o povo indígena Awá-Guajá entre os estados do Maranhão e Pará -, afirma que, seja em condições de estudo acadêmico, seja na elaboração de pareceres e laudos, é o trabalho de campo a base do ofício deste pesquisador. Ela mostra que, nestas situações, os grupos estudados em seus contextos, a partir das categorias e valores próprios destas coletividades, bem como a observação e o diálogo comparativo com a teoria acumulada pela disciplina deram lugar a fatos etnográficos que permitiram o conhecimento e a tradução das categorias de pensamento e das formas de organização sociocultural presentes em terminologia técnica.

Apesar de politicamente definido, o estudo sobre o Massacre de Porongos foi realizado a partir da prevalência dos modelos nativos e da utilização de técnicas de observação etnográfica que permitiram introduzir uma dimensão interpretativa na abordagem de situações sociais. O conhecimento produzido nestes contextos não é aplicado, mas aplicável, com consequências muito reais, mas ainda assim é conhecimento antropológico (Silva 1994). Embora precisemos lidar com certas regras e expectativas que não são definidas no contexto estrito da prática antropológica, não deixamos de nos pautar pelos cânones de nossa disciplina, partilhando de suas potencialidades e limites (Oliveira 1998). 
A necessidade de realização do inventário era vista por alguns apoiadores do pleito pelo memorial e pelo tombamento do Cerro de Porongos como um "entrave burocrático" ao andamento do processo de reconhecimento cultural. A falta de pesquisas acadêmicas que embasassem o pedido de tombamento se colocava como a principal justificativa estatal para a realização dessa investigação. Os sujeitos pesquisados tinham interesse na realização desse estudo, não pela perspectiva de que as relações estabelecidas no contexto da pesquisa propiciassem algum tipo de ascensão social individual mas, principalmente, porque esperavam que ela resolvesse os conflitos (materiais ou simbólicos) que envolviam as suas coletividades de referência, tal como observado por Arruti (2006) em sua pesquisa junto à comunidade negra do Mocambo. Ainda que o trabalho antropológico, neste contexto, deixasse de ser irrelevante para os informantes, e não fosse movido por interesses que não tivessem nada a ver com os deles, muitos foram os desencontros de expectativas, demonstrando que a ironia antropológica a que Geertz (2001) faz menção em suas reflexões sobre as relações com um informante em Java não estava de todo ausente neste processo.

Diante da expectativa de que os antropólogos sejam capazes de adotar um padrão de persuasão discursiva próprio às instâncias do Estado, pautado pelos critérios de verdade e pela linguagem administrativa ou jurídica, é muito pouco provável que seus relatórios abordem também o conjunto de demandas que as coletividades pesquisadas, os apoiadores e os contestadores da demanda, entre outros, fazem a eles ou esperam deles durante a realização dos trabalhos de campo, sob o risco de comprometer a eficácia dessas peças técnicas na produção do convencimento no âmbito administrativo ou jurídico (Arruti 2005).

No entanto, sob o ponto de vista antropológico, são muito importantes as descrições e análises das relações de poder e compromissos (existentes ou imaginados) inerentes à realização desse tipo de pesquisa. Sendo assim, procurei neste artigo apreciar uma experiência etnográfica, trazendo para o centro de minhas considerações aquilo que figura tradicionalmente como pano de fundo sobre o qual se desenvolvem esses estudos: as enormes expectativas geradas a partir de complexos jogos de pressões, negociações, conflitos e disputas entre diferentes grupos sociais. Ao focar as tensões constitutivas dessa inserção, busquei entender melhor os desafios da atuação dos antropólogos nesses processos e como eles são produzidos. Espero que o enfrentamento analítico desses novos contextos e problemas vivenciados pelos antropólogos envolvidos nos processos de mapeamento, identificação e registro do patrimônio cultural afro-brasileiro - do qual este texto tenta fazer parte - possa contribuir para o avanço teórico da disciplina.

Ana Paula Comin de Carvalho é doutora pela Universidade Federal de Rio Grande do Sul e professora adjunta do Curso de Ciências Sociais da Universidade Federal do Recôncavo da Bahia. 


\section{NOTAS}

1 Este texto é uma adaptação de parte de minha tese de doutorado, "O espaço da diferença no Brasil: etnografia de políticas públicas de reconhecimento territorial e cultural negro no Sul do país", defendida junto ao Programa de Pós-Graduação em Antropologia Social da UFRGS em agosto de 2008.

2 Escravos que lutavam sob a promessa de liberdade.

3 Segundo Flores, "a Revolução Farroupilha faz parte dos movimentos liberais que abalaram o Império do Brasil no período regencial, quando explodiram dissensões políticas entre os liberais federalistas e os conservadores unitários nas províncias do Ceará (18311832), Pernambuco (1831-1835), Minas Gerais (1833-1835), Grão-Pará (1835-1840), Bahia (1837-1838), Maranhão (1838-1841) e Rio Grande do Sul (1835-1845)" (Flores 2004: 25). É chamada de Revolução porque implicou a mudança de governo com a instituição do sistema republicano, mas, de acordo com o autor, trata-se de uma guerra civil entre aqueles que aderiram ao movimento e os que não o fizeram.

4 A metodologia empregada nele serviu, inclusive, para a orientação de outra pesquisa sobre as manifestações religiosas relacionadas ao Bará do Mercado Público de Porto Alegre, financiada pela Prefeitura Municipal e realizada no segundo semestre de 2004 pela antropóloga Mariana Balen Fernandes.

5 Vilhena (1997) argumenta que as opções escolhidas pelos folcloristas na política de estruturação institucional dos estudos de folclore no período de 1947 a 1964 determinaram em grande medida o lugar relativamente marginal que eles acabaram ocupando no processo de institucionalização das ciências sociais no Brasil.

6 Dentre eles, Simão (2003).

7 Manifestação cultural religiosa de devoção dos negros que compõem a Comunidade Remanescente de Quilombo de Morro Alto a Nossa Senhora do Rosário e a São Benedito, que mescla elementos africanos e do catolicismo popular, sendo bastante similar às congadas e aos moçambiques existentes em outras regiões do Brasil. Ver Barcellos et al. (2004) e Fernandes (2004).

8 O grupo de pesquisadores, sob a coordenação de Daisy Macedo de Barcellos, na etapa de levantamento preliminar (agosto a dezembro de 2004) foi composto por mim, pelo historiador Vinicius Pereira de Oliveira, pelo então mestrando em Antropologia Social na UFRGS Cristian Jobi Salaini e pela bolsista de campo Maristela Alvarez. Na fase de identificação (setembro de 2005 a abril de 2006) foram agregados à equipe a historiadora Daniela Vallandro de Carvalho, o mestrando em antropologia social da UFRGS Lucas Graeff, as geógrafas Márcia Milene Muller e Ciane Fochesatto e o transcritor Caiuá Al Allam Cardoso. Neste período, apenas Maristela Alvarez não continuou no grupo. Na etapa de documentação (agosto de 2006 a janeiro de 2008), permaneceram no grupo, além de mim, Daisy, Vinicius e Cristian; foram incorporados Mauro Bruschi e a antropóloga Cláudia Turra Magni.

9 Aqui o termo paisagem se refere às formas e objetos da natureza abrangidos num lance de vista.

10 Sobre a importância que a "verdade" sobre este evento histórico assume neste contexto, ver Salaini (2006).

11 Vários textos interessantes sobre esse tema podem ser encontrados em Fleischer, Schuch \& Fonseca (2007). 


\section{BIBLIOGRAFIA}

ABREU, Regina. 2005. “Quando o campo é o patrimônio: notas sobre a participação dos antropólogos nas questões do patrimônio". Revista Sociedade e Cultura 2(8). Goiânia: Departamento de Ciências Sociais, FCHF/UFG.

ARRUTI, José Maurício P. Andion. 2005. "Etnografia e história no Mocambo: notas sobre uma 'situação de perícia'”. In I. B. LEITE (org.). Laudos periciais antropológicos em debate. Florianópolis: NUER/ABA.

. 2006. Mocambo: Antropologia e História do processo de formação quilombola. Bauru: Edusc.

BARCELLOS et al. 2004. Comunidade Negra de Morro Alto. Historicidade, Identidade e Territorialidade. Porto Alegre: Editora da UFRGS/ Fundação Cultural Palmares.

BITTENCOURT Jr., losvaldyr Carvalho. 2006. Maçambique de Osório. Entre a devoção e o espetáculo não se cala na batida do tambor e da maçaquaia. Porto Alegre: UFRGS. Tese de Doutorado em Antropologia Social. Instituto de Filosofia e Ciências Sociais, Universidade Federal do Rio Grande do Sul.

BOURDIEU, Pierre. 1998. O poder simbólico. Rio de Janeiro: Bertrand Brasil.

FERNANDES, Mariana Balen. 2004. Ritual do Maçambique: religiosidade e atualização da identidade étnica na comunidade negra de Morro Alto.Porto Alegre: UFRGS. Dissertação de Mestrado em Antropologia Social. Instituto de Filosofia e Ciências Sociais, Universidade Federal do Rio Grande do Sul.

FLEISCHER, Soraya; SCHUCH, Patrice; FONSECA, Claudia (orgs.). 2007. Antropólogos em ação: experimentos de pesquisa em direitos humanos. Porto Alegre: Ed. da UFRGS.

FLORES, Moacyr. 2004. A Revolução Farroupilha. Porto Alegre: Editora da UFRGS.

FONSECA, Claudia Willians Lee. 2004/2005. "Antropologia e cidadania em múltiplos planos". Revista Humanas 26/27(1/2).

GEERTZ, Clifford. 2001. Nova Luz sobre a Antropologia. Rio de Janeiro: Jorge Zahar.

GRIMSON, Alejandro. 2003. “La nacion después del desconstructivismo. La experiencia argentina y sus fantasmas”. Sociedad (20-21).

L'ESTOILE, Benoit de; NEIBURG, Federico; SIGAUD, Lygia (orgs.). 2002. Antropologia, impérios e estados nacionais. Rio de Janeiro: Relume Dumará/Faperj.

LIMA, Antonio Carlos de Souza Lima. 2002. “Indigenismo no Brasil: migrações e reapropriações de um saber administrativo". In B. L'Estoile, F. Neiburg e L. Sigaud (orgs.). Antropologia,Impérios e Estados nacionais. Rio de Janeiro: Relume Dumará/ Faperj.

O’DWYER, Eliane Cantarino. 2005. “Laudos antropológicos: pesquisa aplicada ou exercício profissional da disciplina?" In I. B. Leite (org.). Laudos periciais antropológicos. Florianópolis: NUER/ABA.

OLIVEIRA, João Pacheco de. 1998. “Uma etnologia dos 'índios misturados'?: situação colonial, territorialização e fluxos culturais". Mana 4(1). 
PEREIRA, Márcio de Azeredo. 2007. “Quem traduz o antropólogo? Considerações sobre o uso da antropologia enquanto técnica". In S. Fleischer; P. Schuch; C. Fonseca (orgs.). Antropólogos em ação: experimentos de pesquisa em direitos humanos. Porto Alegre: Ed. da UFRGS.

RICFUR, Paul. 1997. Tempo e Narrativa - Tomo III. Campinas, São Paulo: Papirus.

SALAINI, Cristian Jobi. 2006. Nossos heróis não morreram: um estudo antropológico sobre formas de ser negro e de ser gaúcho no estado do Rio Grande do Sul. Porto Alegre: UFRGS. Dissertação de Mestrado em Antropologia Social. Instituto de Filosofia e Ciências Sociais, Universidade Federal do Rio Grande do Sul.

$\mathrm{SCHUCH}$, Patrice. 2002. “O 'estrangeiro' em 'campo': atritos e deslocamentos no trabalho antropológico". Revista Antropolítica 12/13.

SILVA, Aracy Lopes da. 1994. “Há antropologia nos laudos antropológico?" In O. S. Silva; L. Luz; C. M. V Helm. A perícia antropológica em processos judiciais. Florianópolis: Ed. da UFSC.

SILVA, Cristhian Teófilo. 2005. “Campo Minado: considerações sobre o poder e a antropologia na identificação e delimitação de terras indígenas". In Antropologia e identificação: os antropólogos e a definição de terras indígenas no Brasil, 1977-2002. Rio de Janeiro: Contra Capa Livraria.

SILVA, Gláucia. 2008. "Introdução". In G. SILVA (Org.). Antropologia extramuros: novas responsabilidades sociais e políticas dos antropólogos. Brasília: Paralelo 15.

SIMÃO, Lucieni de Menezes. 2003. "Os mediadores do patrimônio imaterial". Sociedade e Cultura 6(1). Goiânia: Departamento de Ciências Sociais, FCHF/UFG.

SOUZA, Andréia da Silva Quintanilha (org.). 2005. O negro no Rio Grande do Sul. Minc. Porto Alegre: FCP/IPHAN.

STEIL, Carlos Alberto. 1996. O Sertão das Romarias. Um estudo antropológico sobre o Santuário de Bom Jesus da Lapa. Rio de Janeiro: Ed. Vozes.

TAMASO, Izabela. 2005. "A expansão do patrimônio: novos olhares sobre velhos objetos, outros desafios... (Laudos culturais dos antropólogos inventariantes)". Sociedade e Cultura 8(2).

VELHO, Gilberto. 2007. "Patrimônio, negociação e conflito". In M. F. Lima Filho; J. F. Beltrão; C. Eckert (orgs.). Antropologia e Patrimônio Cultural: diálogos e desafios contemporâneos. Blumenau: Nova Letra/ABA

VILHENA, Luis Rodolfo. 1997. Projeto e Missão: o movimento folclórico brasileiro (1947- 1964). Rio de Janeiro: Funarte: Fundação Getúlio Vargas. 
O que um inventário de referências culturais poderá dizer? Os desafios da atuação dos antropólogos nos processos de mapeamento, identificação e registro do patrimônio cultural das populações afro-brasileiras

RESUMO

Procuro refletir neste artigo sobre os impasses da atuação dos antropólogos nos processos de mapeamento, identificação e registro do patrimônio cultural das populações afro-brasileiras a partir de minha experiência na elaboração do Inventário de Referências Culturais sobre o Massacre de Porongos. Busco apreciar uma experiência etnográfica, trazendo para o centro de minhas considerações aquilo que figura tradicionalmente como pano de fundo sobre o qual se desenvolvem esses estudos: as enormes expectativas geradas a partir de complexos jogos de pressões, negociações, conflitos e disputas entre diferentes grupos sociais. Ao focar as tensões constitutivas dessa inserção, busquei entender melhor os desafios da atuação dos antropólogos nesses processos e como eles são produzidos.

PALAVRAS-CHAVE: etnografia, patrimônio cultural, atuação dos antropólogos.

What could an inventory of cultural references say? Challenges faced by anthropologists working on mapping, identification, and register of African-Brazilian cultural heritage.

ABSTRACT

This article is a reflection, based on my own experience working on the Inventory of Cultural References on the Slaughter of Porongos, on the dilemmas that anthropologists have to face when working in mapping, identification, and register of African-Brazilian cultural heritage. I try to highlight those features that traditionally remain as background on this kind of study: the great expectations generated by the complex games involving pressures, negotiations, conflicts, and disputes between different social groups. Through the focus on these tensions, I try to understand the challenges faced by anthropologists dealing with these processes as well as how they are produced.

KEYWORDS: ethnography, cultural heritage, work of anthropologists.

Recebido em 29/07/2010 